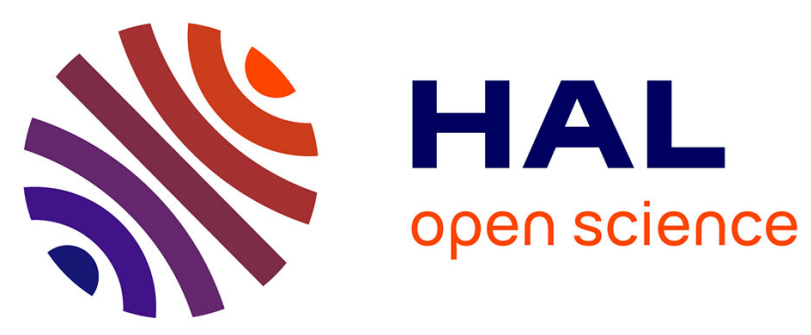

\title{
3D source location using overlapping multipath propagation
}

\author{
Amélie Barazzutti, M M Thode, Kerri D Seger, Jorge Urbán, M M \\ Martínez-Loustalot, M M Esther Jiménez-López, Diana D López-Arzate, \\ Jerome I. Mars
}

\section{To cite this version:}

Amélie Barazzutti, M M Thode, Kerri D Seger, Jorge Urbán, M M Martínez-Loustalot, et al.. 3D source location using overlapping multipath propagation. OCEANS 2017 - OCEANS '17 MTS/IEEE. A Vision for Sustaining our Marine Futures, Jun 2017, Aberdeen, United Kingdom. hal-01552437

\section{HAL Id: hal-01552437 https://hal.science/hal-01552437}

Submitted on 2 Jul 2017

HAL is a multi-disciplinary open access archive for the deposit and dissemination of scientific research documents, whether they are published or not. The documents may come from teaching and research institutions in France or abroad, or from public or private research centers.
L'archive ouverte pluridisciplinaire HAL, est destinée au dépôt et à la diffusion de documents scientifiques de niveau recherche, publiés ou non, émanant des établissements d'enseignement et de recherche français ou étrangers, des laboratoires publics ou privés. 


\title{
3D source location using overlapping multipath propagation
}

\author{
Amélie Barazzutti \\ Environnement Géophysique \\ DGA Engineering \& Integration \\ Paris, 75509 \\ Aaron M Thode \\ Marine Physical Laboratory, Scripps Institution of \\ Oceanography \\ University of California San Diego \\ La Jolla, CA 92093-0206 \\ athode@ucsd.edu
}

\author{
Kerri D. Seger \\ School of Marine Science and Ocean Engineering, \\ University of New Hampshire, \\ Durham, NH 03824 \\ kseger@ccom.unh.edu \\ Jorge Urbán R., Pamela Martínez-Loustalot, M. Esther \\ Jiménez-López and Diana López-Arzate \\ UABCS Mamiferos Marinos Lab
}

\author{
Jérôme I. Mars \\ Univ. Grenoble Alpes, CNRS, Grenoble-INP, Gipsa-lab, F38000 France \\ jerome.mars@gipsa-lab.gr.fr
}

\begin{abstract}
In passive acoustic monitoring, source localization using multipath propagation can be challenging whenever the source-receiver configuration leads to overlapping multipath arrival patterns. We propose a single-hydrophone model-based method with matched-impulse response (IR) processing that exploits unresolved multipath arrival patterns to locate the source in 3D, making the best use of the bathymetric information as well as the time differences of groups of arrivals. When only groups of paths are resolved, the identity of the paths constituting the groups remains unknown, preventing the use of classical localization methods. To overcome this critical limitation, we apply an approach based on the characterization of groups of paths to estimate the source location.
\end{abstract}

Keywords—underwater acoustics, source localization, warping

\section{INTRODUCTION}

In underwater acoustics, source localization is one of the first necessary steps for applications like passive acoustic monitoring or geoacoustic inversion. The feasibility of using a single receiver for range and depth estimation has been demonstrated in ray theory ([1], [2], [3]). While 3D (range, depth, azimuth) localization usually requires a vertical or horizontal array, more recent work has demonstrated its feasibility with a single receiver by using azimuth-dependent bathymetric information for bearing estimation [4]. Reference [4] uses sperm whale click multipath arrival patterns to locate the whale with a single receiver, by comparing the detected click arrival pattern to predicted arrival patterns from candidate sources to estimate the best match. Thanks to the diverse bathymetric information in the area, the localization of the sperm whale could be done in $3 \mathrm{D}$ space around the receiver.
However, in long-range acoustical studies, source localization can become challenging whenever the sourcereceiver configuration leads to unresolved paths (different multipath arrivals that overlap in time). In such a situation, the multipath arrivals cannot be distinguished due to an incomplete time separation. Localization mistakes will result if the multipath arrivals are supposed to be separated yet do not appear that way in the data. Warping operators can be used to distinguish these arrivals in mode theory ([5]) as well as in ray theory ([6]). Though, a full resolution of the multipath arrival pattern is not always assured.

This work describes a new algorithm that allows source localization for distant emissions inferring a non-resolved multipath arrival pattern. We combine the use of warping operators and the use of the bathymetric information into a single-receiver model-based algorithm. The $3^{\text {rd }}$ dimension (bearing) can be reached whether the bathymetric information is sufficiently variable with respect to azimuth. Time warping operators are used to enhance the impulse response (IR) of the channel and to extract a sufficient number of groups of arrival times to localize the source. The bathymetric environment, as well as a mean sound speed profile, is required for this approach to be successful. However, no bottom environmental parameters need to be known, since only the time features of the IR are needed. We illustrate the 2D (range and depth) performances of the algorithm in a simulated environment, and then present initial results for a biological source.

\section{THEORY AND PROCEDURE}

Tiemann et al. [4] used sperm whale click multipath arrival patterns to locate the whale with a single receiver, comparing 
the detected click arrival pattern with predicted arrival patterns from candidate sources to estimate the best match. Thanks to the bathymetric variability in the area, the source (sperm whale) could be localized in the 3D space (range, depth, azimuth) around the receiver.

In the present work the signals considered for localization are not short-duration clicks like in [4], but rather frequencymodulated (FM) signals emitted by distant sources, so that the arrival pattern can only be resolved into clusters of overlapping individual arrivals. Nevertheless, the same localization principle as in [4] can be applied to the clustered (unresolved) multipath arrival patterns. The localization algorithm can be decomposed into two steps. Each detected signal is processed individually according to these steps.

\section{A. Time Warping for IR estimation}

The first step is the estimation of the observed IR using previous works ([6]). Custom-made time warping operators $\mathrm{W}$ are defined for each frequency modulation $\mathrm{s}(\mathrm{t})=\exp (2 \pi j \phi(\mathrm{t}))$, with the time variable substitution: $t \stackrel{w}{\rightarrow} \phi^{-1}\left(f_{w} w\right)$ where $f_{w}$ is the warping frequency. The warping operator that changes the signal into a pure frequency is $w(t)=$ $\varphi(t) / f_{w}$ with the warping frequency $f_{w}$ chosen so that $w(0)=0$ and $\mathrm{w}(\mathrm{T})=\mathrm{T}, \mathrm{T}$ the duration of the warping.

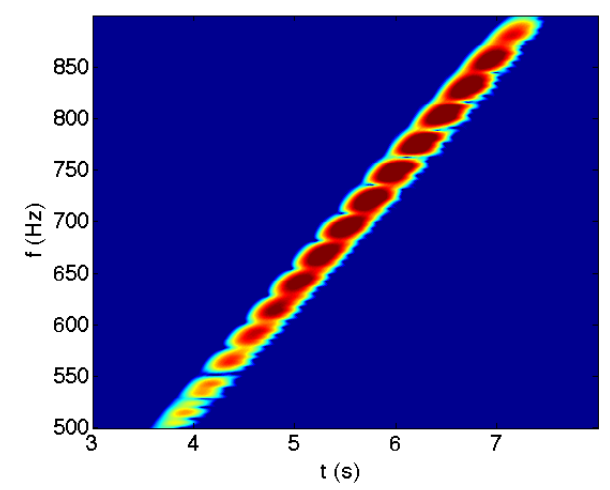

Fig. 1. TFR for playback simulation (source is $5 \mathrm{~m}$ depth and $1.3 \mathrm{~km}$ distant from a receiver located $5 \mathrm{~m}$ above the ocean floor).

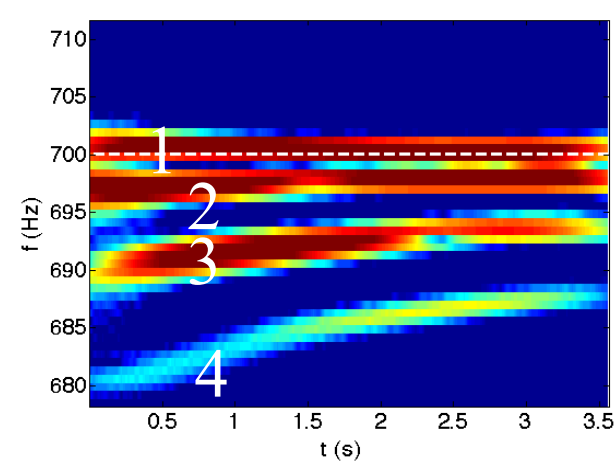

Fig. 2. Warping snapshot at the first arrival detected. The echos are identified from 1 to 4 . The 1 st echo is a pure frequency at the warping frequency while the others are curved.

In the passive context, the first detected echo is used as the signal reference, since the structure of the emitted signal is unknown.
The warping operator $\mathrm{w}$ is applied on a sliding window. At each temporal bin $\mathrm{n} / \mathrm{fe}(\mathrm{n}=1: \mathrm{N}-\mathrm{T}$.fe, fe the sampling rate), the signal is warped. Then, the warped spectral amplitudes are filtered and integrated at the warping frequency to estimate the IR. Since the successive echoes are the copies of the first detected echo, they will correspond to a peak in the IR (see the black curve representing the observed IR in Fig. 3). However, in the source-receiver geometry considered in this paper, this procedure is still insufficient to fully separate the individual paths (see red peaks representing the theoretical IR in Fig. 3).

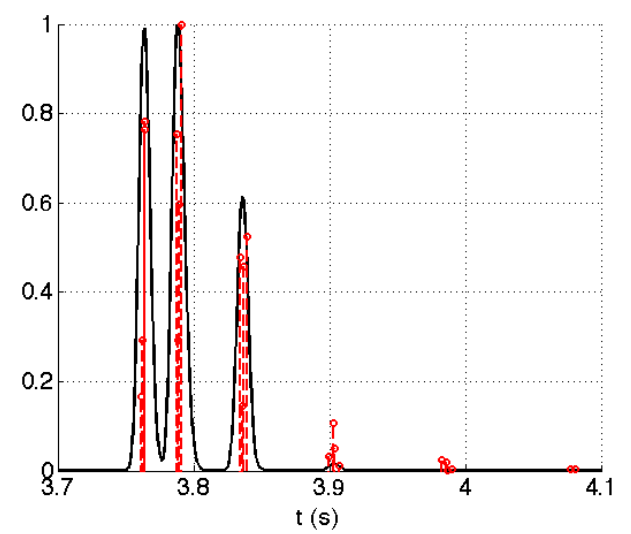

Fig. 3. Observed IR (black line) and theoretical IR (in red) illustrating the group arrival pattern instead of individual path arrival pattern. The propagated signal is shown in Fig. 1. The source is placed at $2 \mathrm{~km}$ range and $30 \mathrm{~m}$ deep in $100 \mathrm{~m}$ water depth, with the receiver placed $5 \mathrm{~m}$ above the sea bottom.

\section{B. Ambiguity surface estimation}

In a next step, a 2D (range and depth) ray-tracing model predicts the multipath arrivals that would be received from simulated sources on a grid in three dimensions (depth, range, azimuth) around the fixed receiver. This replica set calculation has to be computed for every bathymetry/receiver location set.

Finally, the observed arrival pattern of unresolved multipath is compared to each simulated arrival pattern of resolved multipath from the replica set. As individual ray arrivals are not always observable, the assumption is made that the arrival time for a group of individual arrivals can be approximated by the mean of the $\mathrm{N}_{\mathrm{j}}$ times of arrival composing the group. A cost function $\mathrm{C}_{\mathrm{r}, \mathrm{z}, \mathrm{p}}$ is associated to each replica according to its distance to the observation:

$$
C_{r, z, p}=\sqrt{\sum_{j}\left(\sum_{i} \frac{\text { toa }_{i, j}}{N_{j}}-\operatorname{tg}_{j}-\delta_{o p t}\right)^{2}}
$$

with toa $a_{i, j}$ defined as the ith time of arrival associated with the closest observed group of paths $\mathrm{tg}_{\mathrm{j}}$, and $\delta$ opt is an optimized parameter to position the start of the simulated IR with the start of the observed one (see figure 4).

As observed by [4], similar bathymetric profiles will lead to a spread of the localization estimation, giving only access to the range and the depth of the source. However, when varied enough, the azimuthal-dependent bathymetry of the environment also provides information about the bearing (azimuth) of the source using only one receiver. 


\section{PERFORMANCE PREDICTIONS}

The passive aspect of this work implies two main difficulties. First, the frequency modulated structure of the signal, needed to build the time warping operator, is unknown. Second, the IR used to locate the source is not literally a multipath arrival pattern but rather a "multigroup" arrival pattern, which leads to potential localization ambiguities.

\section{A. Frequency modulation estimation}

In passive acoustics, the signal source structure is unknown; therefore, the frequency modulation of the first detected arrival is used as the reference for the successive echoes (see II.A). The warping operator $\mathrm{w}$ is designed according to this first-arrival structure, which can be automatically traced using track tracing algorithms ([8],[9]). Differences between the modulation structure of the source signal and the first detected arrival will distort the warping signal and consequently degrade the IR estimate. Defining g as the frequency law for a given signal $s(t)$ will lead to the following the frequency modulation transformation: $\mathrm{s}(\mathrm{t})=\exp \left(2 \pi \mathrm{j}\left(\phi \circ \mathrm{g}^{-1}\right)\left(\mathrm{f}_{\mathrm{w}} \mathrm{t}\right)\right) \quad$ instead of $s(t)=\exp \left(2 \pi j\left(\phi \circ \phi^{-1}\right)\left(f_{w} t\right)\right)$. The echoes will not be transformed into the pure frequency $f_{w}$, and the IR will be incorrect.

\section{B. "Multigroup" arrival pattern}

The multipath arrival pattern is assessable as soon as the signal processing resolution distinguishes the individual arrivals.

For some source-receiver configurations, such as longdistance sources emitting close to the surface or ocean bottom, close individual arrivals will be perceived by the processing tools as a single group of unresolved unidentified arrivals. We consider a Pekeris environment with $b=100 \mathrm{~m}$ water depth and a homogenous sound speed $\mathrm{c}$ of $1500 \mathrm{~m} / \mathrm{s}$. A single receiver is located at $\mathrm{a}=80 \mathrm{~m}$ depth. In these ideal conditions, we neglect ray refraction so that the sound propagation is linear. The range $r$ and the depth $d$ of the source can be estimated using reference [1]'s method:

$$
\begin{gathered}
r=\frac{\left(\frac{c \cdot \tau_{1 b}}{2}\right)^{2}+b \cdot(a-b)-\left(\frac{c \cdot \tau_{1 s}}{2}\right)^{2} \cdot\left(1-\frac{b}{a}\right)}{\frac{c \cdot \tau_{1 s}}{2} \cdot\left(1-\frac{b}{a}\right)-\frac{c \cdot \tau_{1 b}}{2}} \\
d=\frac{\left(\frac{c \cdot \tau_{1 b}}{2}\right)^{2}+\left(\frac{c \cdot \tau_{1 b}}{2}\right) \cdot r}{a-b}+b
\end{gathered}
$$

with $\tau_{1 \mathrm{~b}}$ and $\tau_{1 \mathrm{~s}}$ as the first time differences of arrival.

Fig. $4 \mathrm{~A}$ and $\mathrm{B}$ illustrate the limitations of time difference exploitation. We applied the time resolution of the time warping preprocessing used in the localization algorithm (see [6] for details). For a source at $2000 \mathrm{~m}$ range and $30 \mathrm{~m}$ depth, the observed times of arrival obtained after the warping preprocessing will be the mean arrival time of the first three overlapping paths (direct, first surface and first bottom reflected paths) and the fourth path. Using (2) and (3) with the observed time differences of arrival will lead to a wrong estimation of $550 \mathrm{~m}$ range and $48 \mathrm{~m}$ depth.
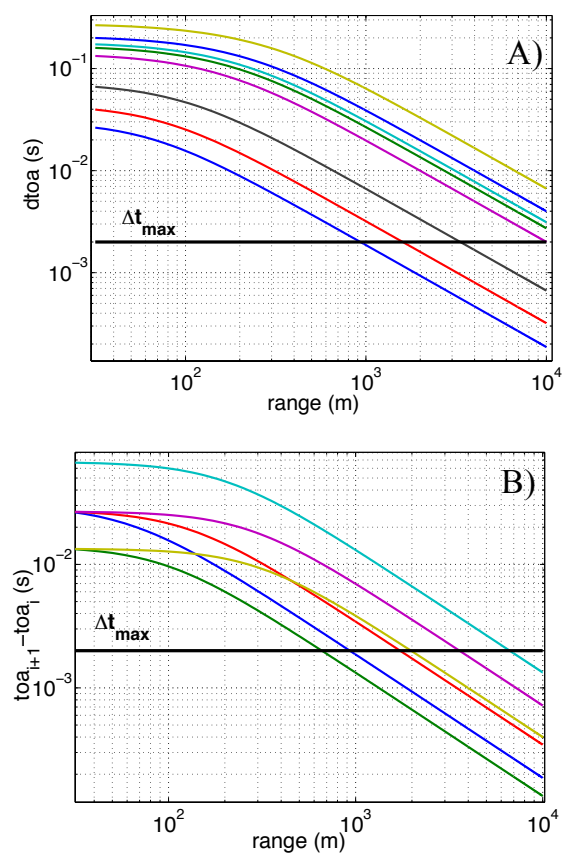

Fig. 4. A) Time differences of arrival according to the source-receiver range. B) Arrival time proximity according to the source-receiver range. The black horizontal line is the resolution limit of the warping preprocessing used in the localization algorithm (see [6]). The colored lines correspond respectively to the succesive time differences of arrival (tdoa) and toa proximity.

\section{SIMULATION IN A FLAT BATHYMETRIC ENVIRONMENT}

In this section, a flat bathymetric environment is used to analyze the range and depth estimation performances of the algorithm. This test case is chosen as representative of a real controlled data set from ERATO 2011 experiment in the Gulf of Lion (see [10] for the experiment description). The real data applications will be the subject of forthcoming publications.

\section{A. Simulation content}

The simulated signal was an FM sweep ([1-2 kHz], $0.05 \mathrm{~s}$ duration), representative of dolphin whistle features. The simulated source was placed at $20 \mathrm{~m}$ depth and successive ranges between $200 \mathrm{~m}$ and $8 \mathrm{~km}$.

The propagation was simulated in a flat bathymetric environment, representative of the Gulf of Lion (Mediterranean sea). A simplified sound speed profile based on observations in the Gulf of Lion was defined and the water depth is homogenous at approximately $100 \mathrm{~m}$. A single receiver was placed at $82 \mathrm{~m}$ depth, depth of one of the real hydrophones. The ray-tracing model Bellhop (C) was used with this representative environment to produce both the simulated signals and the IR replica set needed by the algorithm. The replica set was established on a regular grid with 10-meter steps for the range dimension and one-meter steps for the depth dimension.

\section{B. Results}

Fig. 5 shows the localization algorithm results for each simulated location. 


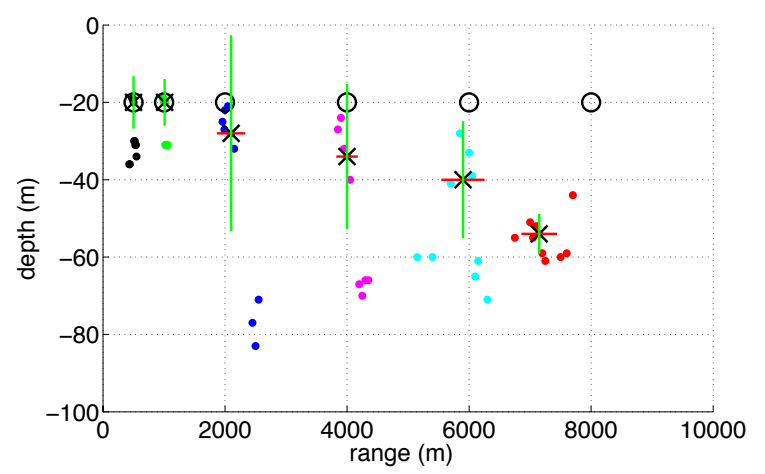

Fig. 5. Simulation results in a flat bathymetric environment represented in the range/depth space. The real locations are represented as wide black circles. The best estimates are represented as black cross. The standard deviation on range (red) and depth (green) estimation, considering the ten best positions, are displayed as centered on the best estimate. The ten best locations for each position are represented with colored dots.

Despite only one receiver and a degraded IR that does not give access to the multipath arrival pattern, the algorithm allows a good range estimation in a flat bathymetric environment with a maximum error of $\sim 10 \%$ at $8 \mathrm{~km}$. The depth estimation was good at short ranges, but declined with long ranges. We observed the presence of secondary minima as predicted in section III.

This simulated test case demonstrated the feasibility of long-range range and depth estimation using a single receiver and unresolved multipath propagation. In this case, without any bathymetric plus-value information, the localization remains in 2D.

\section{PRELIMINARY RESUltS ON REAL DATA IN A COMPLEX BATHYMETRIC ENVIRONMENT}

Next, we applied the algorithm to the complex bathymetric environment of the Los Cabos area near Cabo San Lucas area (México). This section shows the first results on a true biological source. The complete details of the real data applications will be the object of forthcoming publications.

\section{A. Los Cabos environment}

Fig. 6 presents the bathymetry of the Los Cabos area based on the 30 " resolution GEBCO bathymetry. Passive acoustic monitoring of humpback whales takes place in this area [11]. In this area, we utilize a data set from an experiment collected by the Scripps Institution of Oceanography (SIO) and the Autonomous University of Southern Baja California (UACBS) in 2013. Numerous humpback whale calls have been recorded at the "Punta Gorda" site, on a receiver close to the bottom (approximately 5 meters).

\section{B. Localization in a diverse bathymetric environment}

The signal of interest is an FM humpback whale call (350$650 \mathrm{~Hz}$ bandwidth; $0.5 \mathrm{~s}$ duration) that exhibits multipath propagation (Fig. 7). We applied the algorithm on this call. As in the previous test case, the ray-tracing model BELLHOP $\odot$ was used to compute the replica set around the hydrophone. It integrates the 30-arcseconds-resolution GEBCO bathymetry (The GEBCO, www.gebco.net). A low-resolution grid has been defined every 10 degrees all around the hydrophone to initialize the search. This first search has identified a privileged sector in which we have launched the algorithm on a finer grid.

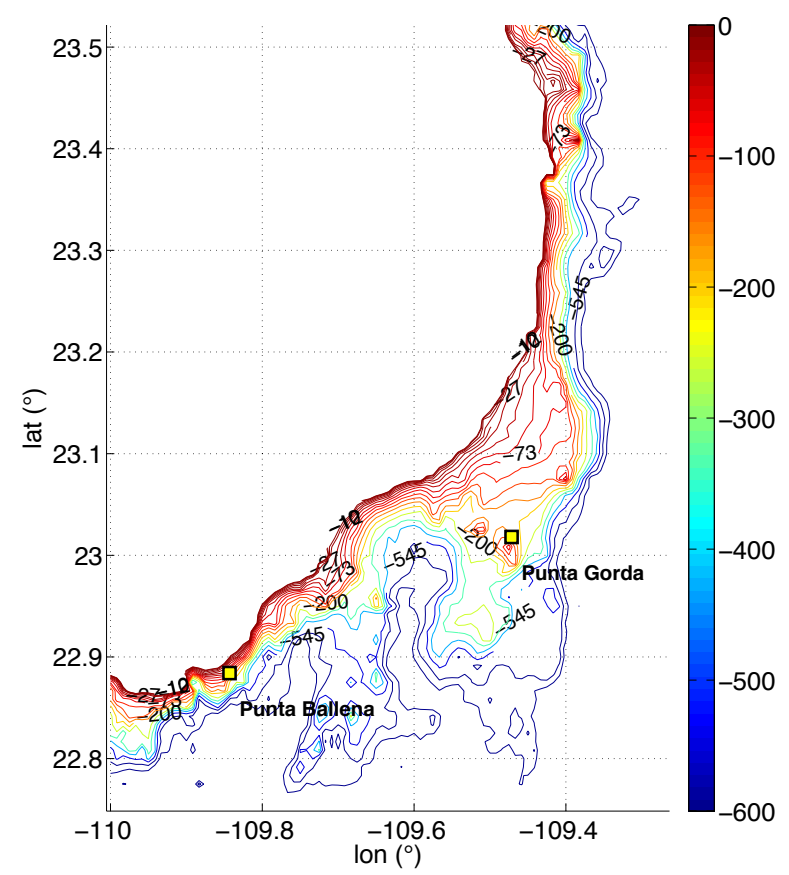

Fig. 6. Cabo San Lucas area bathymetry (The GEBCO, www.gebco.net, 30", resolution) along with the positions the two receivers Punta Ballena and Punta Gorda (yellow squares).

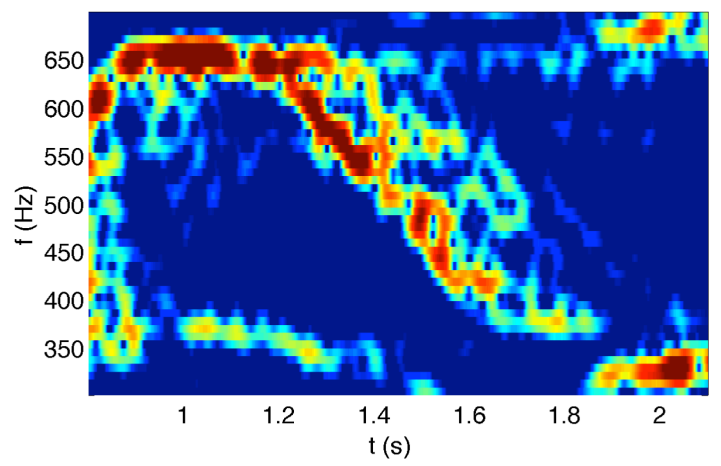

Fig. 7. Humback whale call registered in the Los Cabos area in 2013 by SIO and UABCS at the Punta Gorda location.

Fig. 8 presents the range estimation for the processed call. The best estimated location (black star) is contained in a restricted area. The whale was localized within a circle of 1.5 $\mathrm{km}$ radius and within the first 20 meters of depth. This localization performance is compatible with similar results obtained by [12] on long-range right whale localizations.

As expected for long-distance sources, the degraded IR estimate yields multiple possible locations. The cost function is therefore plotted as a series of contours. White areas are areas excluded by the algorithm (e.g. too short of a candidate IR to match the observed degraded IR). However, thanks to the 
bathymetric information, which varies from one bearing to another on the simulation grid, a restricted area can be identified using only one receiver.

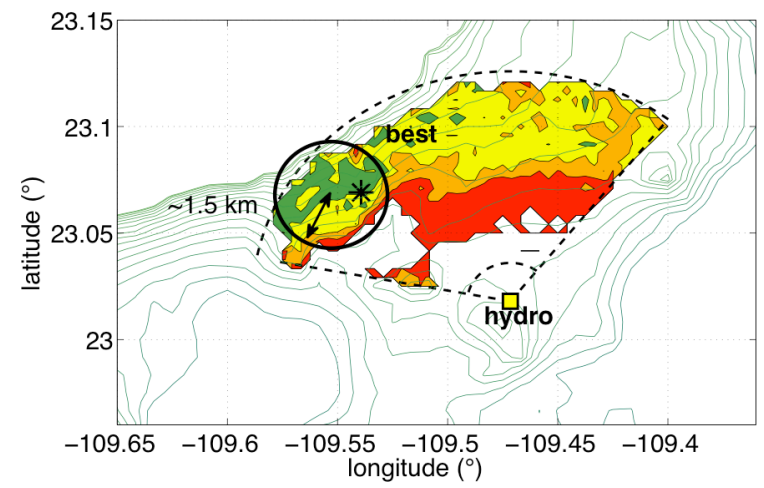

Fig. 8. Range estimation for the processed humpback whale call in Fig. 7. The ambiguity surface is displayed as colored contours: green contours costs smaller than 1.5 times the minimum cost encountered, yellow contours costs twice the minimum cost, orange contours costs 3 times the cost, and red contours the remaining cost values. White areas are not compatible with the observed IR. The range is estimated to be around $10 \mathrm{~km}$ inside the green contoured area.

\section{DISCUSSION}

Underwater long-distance source localization using ray theory can be challenging whenever the multipath arrival pattern cannot be resolved in detail. In this paper we present an innovative method that allows source localization using a single hydrophone. Time-warping preprocessing allows enhancing the arrival pattern description, though not enough to fully time-separate individual arrivals, yielding a degraded IR. An adapted matched-impulse response processing has been defined to make the best use of the degraded IR to estimate the source location. With a sufficiently varied bathymetry, the algorithm leads to a 3D localization. The algorithm requires the sound speed profile and the bathymetry, but does not require knowledge nor modeling of geoacoustical bottom features, since only the arrival time patterns are used in the algorithm. The limits of the method are known. The passive context forces the use of the first detected echo as a reference for he signal. The use of low-resolution multipath patterns precludes a unique solution for the optimal position.

The feasibility of this approach has been evaluated on simulated data in a flat environment, demonstrating the feasibility of localization in 2D even at long distance. Promising results have been shown on a Humpback whale FM call propagating through the complex bathymetric environment of Los Cabos, providing a 3D estimate with a $1.5 \mathrm{~km}$ radius resolution.

\section{REFERENCES}

[1] R. Aubauer, M. O. Lammers, and W. W. Au (2000). One-hydrophone method of estimating distance and depth of phonating dolphins in shallow water. The Journal of the Acoustical Society of America, 107(5), 2744-2749.

[2] C. Laplanche, O. Adam, M. Lopatka, and J. Motsch, "Male sperm whale acoustic behavior observed from multipaths at a single hydrophone," J. Acoust. Soc. Am. 118, 2677-2687 2005

[3] A. Barazzutti, C. Gervaise, JP. Sessarego, Y. Stephan, "Field application of a passive geoacoustic inversion in shallow waters using marine mammals-like signals and a single hydrophone", in proceeding of the $1^{\text {st }}$ Underwater Acoustic Conference, Corfu (Greece), 2013

[4] C. O. Tiemann, A.M. Thode, J. Straley, V., O'Connell, and K. Folkert, "Three-dimensional localization of sperm whales using a single hydrophone". The Journal of the Acoustical Society of America. 120 (4), 2355-2365, oct. 2006

[5] J. Bonnel, and N. R. Chapman: "Geoacoustic inversion in a dispersive waveguide using warping operators", Journal of the Acoustical Society of America, 130, (2), pp. EL101-EL107. 2011.

[6] A. Barazzutti, C. Gervaise, J. I. Mars: "Utilisation de warping temporel pour étendre le domaine de fonctionnement d'un procédé d'inversion géoacoustique passive". Traitement du Signal. 33(1), 2016.

[7] J. Bonnel, A. M. Thode, S. B. Blackwell, K., Kim, and A., Michael Macrander, "Range estimation of bowhead whale (Balaena mysticetus) calls in the Arctic using a single hydrophone". The Journal of the Acoustical Society of America. 136(1), 145-155, jul. 2014

[8] T. Lampert, and S. O'Keefe, "A survey of spectrogram track detection algorithms", Applied Acoustics, 71(2), 87-100, 2010

[9] F. Dadouchi, C. Gervaise, C. Ioana, J. Huillery, and J. I. Mars, "Automated segmentation of linear time-frequency representations of marine-mammal sounds", The Journal of the Acoustical Society of America, 134(3), 2546-2555, 10.1121/1.4816579. vi, 2013

[10] A. Barazzutti, C. Gervaise, JP. Sessarego, and Y. Stephan: "Field application of a passive geoacoustic inversion in shallow waters using marine mammals-like signals and a single hydrophone", in proceedings of the Underwater Acoustic Conference 2013, Corfu (Greece)

[11] M. E. Jiménez-López, "Uso de hábitat de madres con cría y machos cantores de ballena jorobada (megaptera noveaengliae) en la región de los cabos, baja california sur durante el invierno 2004", Ph.D. thesis, Tesis de Maestría, Universidad Autónoma de Baja California Sur, México. xi, 2006

[12] C Gervaise, S Vallez, Y Stephan, and Y Simard: "Robust 2D localization of low-frequency calls in shallow waters using modal propagation modelling", Canadian Acoustics, [S.1.], v. 36, n. 1, p. 153159, mar. 2008. ISSN 2291-1391

[13] J. Bonnel, C., Gervaise, P., Roux, B., Nicolas, and J. I. Mars, "Modal depth function estimation using time-frequency analysis". The Journal of the Acoustical Society of America, 130, (1), pp. 61-71, 2011

[14] J. Bonnel, A. M., Thode, and S. B. Blackwell, "Range estimation of bowhead whale (Balaena mysticetus) calls in the Arctic using time warping on a single hydrophone", The journal of the Acoustical Society of America, 136, (1), pp. 145-155, 2014

[15] J. Bonnel, B., Nicolas, J. I., Mars, and S.C. Walker, S.C.: "Estimation of modal group velocities with a single receiver for geoacoustic inversion in shallow water", The Journal of the Acoustical Society of America, 128, (2), pp. 719-727. 2010. 